\section{ECCOMAS} Proceedia
COMPDYN 2021 Computational Methods in Structural Dynamics and Earthquake Engineering M. Papadrakakis, M. Fragiadakis (eds.) Streamed from Athens, Greece, 28 - 30 June 2021

\title{
DEBONDING ANALYSIS OF FRCM COMPOSITES FOR STRUCTURAL UPGRADING OF RC STRUCTURES
}

\author{
Maria Teresa Cristofaro' ${ }^{1}$, Angelo D'Ambrisi ${ }^{1}$, Francesco Focacci $^{2}$, Raffaele Nudo ${ }^{1}$, \\ Gianfranco Stipo ${ }^{1}$, Marco Tanganelli ${ }^{1}$, Mario De Stefano ${ }^{1}$ \\ ${ }^{1}$ Dipartimento di Architettura, Università di Firenze \\ piazza Brunelleschi 6, 50121 Firenze, Italy \\ mariateresa.cristofaro@unifi.it \\ ${ }^{2}$ Università eCampus \\ via Isimbardi 10, 22060 Novedrate (CO), Italy \\ francesco.focacci@uniecampus.it
}

\begin{abstract}
Fiber Reinforced Cementitious Matrix (FRCM) materials are currently widely used for strengthening reinforced concrete $(R C)$ structures and have assumed an important role in the seismic upgrading of these structures. The mechanical parameters for the evaluation of the capacity of strengthened structures, such as the tensile strength and the debonding load of the strengthening material, are determined through standards testing procedures that usually include tensile tests and bond tests. In this work the results of an experimental campaign of beam tests on RC elements strengthened with FRCM composites are presented. Different strengthening configurations and load rates are adopted. The experimental results are discussed and compared with the results available in literature to assess the influence of the testing procedure on the obtained mechanical parameters.
\end{abstract}

Keywords: FRCM composites, RC structures, Experimental campaign, Beam test. 


\section{INTRODUCTION}

Fiber reinforced polymers (FRP) [1, 2] and fiber reinforced cementitius matrix (FRCM) materials $[3,4]$ are widely used for strengthening and repairing masonry and reinforced concrete $(\mathrm{RC})$ structures. The former are made of continuous fibers embedded in a polymeric matrix, while the latter consist of continuous fibers arranged in unidirectional or bidirectional textiles embedded in a cement based matrix. FRCM materials are effective in increasing the flexural $[5,6,7,8,9,10]$ and the shear $[11,12,13]$ capacity of RC members.

Guidelines have recently been issued for the mechanical characterization and evaluation of the design parameters of FRCM materials [14, 15]. Italian guideline [14] provides for tensile tests both on textiles and on composites and direct shear tests, while US guideline [15] provides for tensile tests on composites and tests on structural elements.

The effectiveness of composite materials in increasing the capacity of concrete and masonry structural elements strongly depend on the bond properties between composite and substrate (FRP) $[1,16,17]$ and between fibers and matrix (FRCM) [18, 19].

The shear stress transfer at the reinforcement-substrate interface is experimentally studied through direct shear tests in the single-lap configuration [20, 21, 22, 23, 24, 25, 26] (Figure 1a) or double-lap [27, 22] configuration (Figure 1b). These tests are performed to determine the debonding mechanism, i.e. the interface where debonding occurs, the maximum force transferable at the interface named joint capacity, the maximum force transferable when debonding initiates named debonding load $[13,26]$, and the minimum length of the interface surface to obtain the bond capacity named effective bond length. The tests performed so far have shown that for many FRCM materials the debonding occurs at the interface between fiber and matrix with significant relative displacements of the fibers with respect to the matrix and without debonding of the matrix from the support [28, 29].

The results of the single-lap or double-lap shear tests can be used to calibrate a cohesive material law $(\mathrm{CML})[30,24,26]$, i.e. a relationship between the interfacial shear stress $(\tau)$ and the relative displacement or slip (s) between the fibers and the substrate. In the case of FRCM materials that show a loss of bond at the interface between fibers and matrix, the CML allows to predict with reasonable accuracy the tensile response obtained through tensile tests [31] performed according to ACI 434 [15].

(a)

(b)
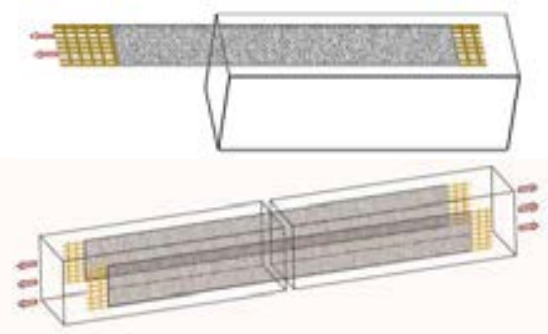

(c)

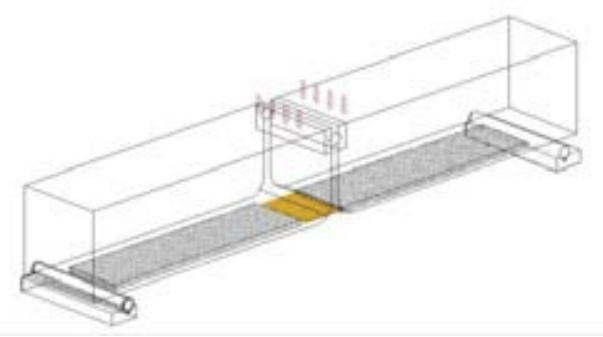

Figure 1. Typical test setup for (a) single-lap shear test, (b) double lap shear test, and (c) beam test.

An alternative to direct shear tests for the evaluation of the interfacial properties is the indirect shear test performed on specimens of the beam test type [32, 33, 34] (Figure 1c). The beams are made up of two concrete blocks connected by a hinge in the compression zone and by the reinforcement in the tensile zone and are subjected to bending test on 3 or 4 load points. The tensile force in the composite material is determined as a function of the applied force $F$ through the equilibrium conditions.

In this work the results of an experimental campaign of beam tests on a FRCM material with poliparafenilenbenzobisoxazole (PBO) fibers are presented. With regard to the bond 
properties of PBO-FRCM materials, many experimental results can be found in literature [13]. In particular the results of single-lap shear tests performed with different bond lengths are reported in [25]. In [26] the results presented in [25] are used to calibrate an interfacial CML based on the relationship between bond length and joint capacity. In $[22,33]$ the results of single-lap shear tests are compared with the results of double-lap shear tests. In [35] the dependence of the joint capacity evaluated with single-lap shear test on the loading rate is highlighted. Finally in [33] beam test results are compared with single-lap shear test results and it is observed that these two tests provide comparable results in terms of debonding load and joint capacity.

The experimental campaign presented in this paper includes beam tests on PBO-FRCM materials characterized by three different PBO textiles embedded in the same cement matrix. The tests were performed at different loading rates. The obtained experimental results are discussed and compared with the experimental results available in literature with the following aims: i) to compare the dependence of the joint capacity on the loading rate obtained with single-lap shear tests with the dependence of the joint capacity on the loading rate obtained with the beam test; ii) to assess the influence of the fiber arrangement in textiles on the fiber stress associated with the joint capacity; iii) to compare the results of single-lap shear tests with the results of beam tests in terms of joint capacity.

\section{EXPERIMENTAL PROGRAM}

\subsection{Materials}

Three different PBO textiles (Figure 2) embedded in the same cement matrix were used in the experimental campaign: i) bidirectional textile with $70 \mathrm{~g} / \mathrm{m}^{2}$ of fiber in the longitudinal direction (equivalent thickness of $0.046 \mathrm{~mm}$ ) and $18 \mathrm{~g} / \mathrm{m}^{2}$ of fibers in the transversal direction (equivalent thickness of $0.012 \mathrm{~mm}$ ); ii) unidirectional textile with $44 \mathrm{~g} / \mathrm{m}^{2}$ of fibers (equivalent thickness of $0.028 \mathrm{~mm}$ ); iii) unidirectional textile with $105 \mathrm{~g} / \mathrm{m}^{2}$ of fibers (equivalent thickness of $0.067 \mathrm{~mm}$ ).

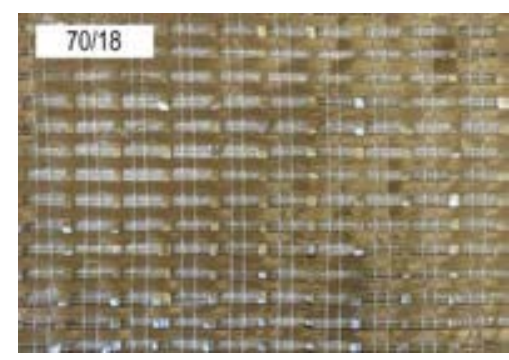

(a)

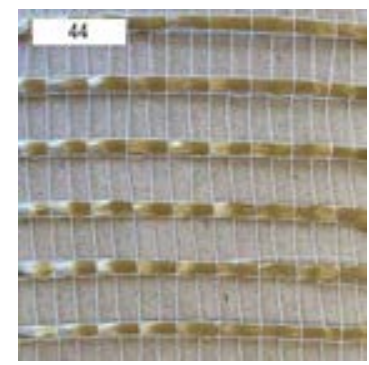

(b)

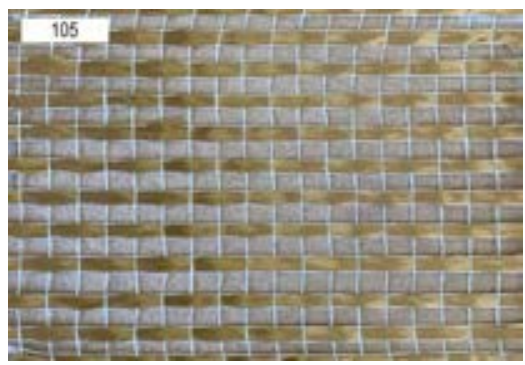

(c)

Figure 2. PBO textiles used in the tested FRCM materials: (a) bidirectional textile with $70 \mathrm{~g} / \mathrm{m} 2$ of fibers in the longitudinal direction and $18 \mathrm{~g} / \mathrm{m} 2$ of fibers in the transversal direction; (b) and (c) unidirectional textiles with 44 $\mathrm{g} / \mathrm{m} 2$ and $105 \mathrm{~g} / \mathrm{m} 2$ of fibers in the longitudinal direction, respectively.

These PBO textiles are referred to as $70 / 18,44$, and 105 , respectively. The main geometrical and mechanical properties of the PBO textiles are summarized in Table 1 , where $b^{*}, t^{*}$ and if are the width, thickness and center-to-center distance of the longitudinal yarns, respectively, while $\mathrm{tf}$ is the equivalent thickness defined as the cross section area per unit width, equal to $t^{*} b^{*} / i_{f}=p / \gamma_{f}$, where $\mathrm{p}=70,44$, or $105 \mathrm{~g} / \mathrm{m} 2$ is the weight of the longitudinal fibers per unit surface of the textile and $\gamma_{f}=1.56 \mathrm{~g} / \mathrm{cm}^{3}$ is the unit weight of the PBO fibers. $E_{f}$ is the elas- 
tic modulus of the PBO fiber assumed equal to $206 \mathrm{GPa}$ according to the tensile tests presented in [25], while $f_{t}$ is the fiber tensile strength according to the manufacturer.

\begin{tabular}{lccccccc}
\hline PBO textile & $\begin{array}{c}p \\
{\left[\mathrm{~g} / \mathrm{m}^{2}\right]}\end{array}$ & $\begin{array}{c}b^{*} \\
{[\mathrm{~mm}]}\end{array}$ & $\begin{array}{c}t^{*} \\
{[\mathrm{~mm}]}\end{array}$ & $\begin{array}{c}i_{f} \\
{[\mathrm{~mm}]}\end{array}$ & $\begin{array}{c}t_{f} \\
{[\mathrm{~mm}]}\end{array}$ & $\begin{array}{c}E_{f} \\
{[\mathrm{GPa}]}\end{array}$ & $\begin{array}{c}f_{t} \\
{[\mathrm{GPa}]}\end{array}$ \\
\cline { 1 - 6 } $70 / 18$ & 70 & 4 & 0.1081 & 9.5 & 0.046 & & \\
\cline { 1 - 6 } 44 & 44 & 4 & 0.1645 & 23.5 & 0.028 & & \\
\cline { 1 - 6 } 105 & 105 & 4 & 0.1508 & 9 & 0.067 & & \\
\hline
\end{tabular}

Table 1. Geometrical and mechanical properties of the three different PBO textiles.

The cement based matrix was characterized through three-point bending tests and compression tests [36]. The performed tests provided an average compressive strength of 29.13 $\mathrm{MPa}$ and an average tensile strength of $6.40 \mathrm{MPa}$. The concrete blocks were casted with a commercial mix design (BIGMAT C25/30 concrete) with the addition of $20 \%$ river sand (grain size of $0.3 \div 1.25 \mathrm{~mm}$ ) to obtain strength values close to those of existing concretes. Simultaneously to the block casting, 20 cubes with a side of $150 \mathrm{~mm}$ were casted. The compression tests of these cubes provided an average compressive strength [37] of $17 \mathrm{MPa}(\mathrm{CoV}$ $11 \%)$.

\subsection{Test setup}

The bond length $L$ was the same for the two blocks and was equal to $363 \mathrm{~mm}$ while the width of the strip was equal to $94 \mathrm{~mm}$ (Figure 3).

(a)

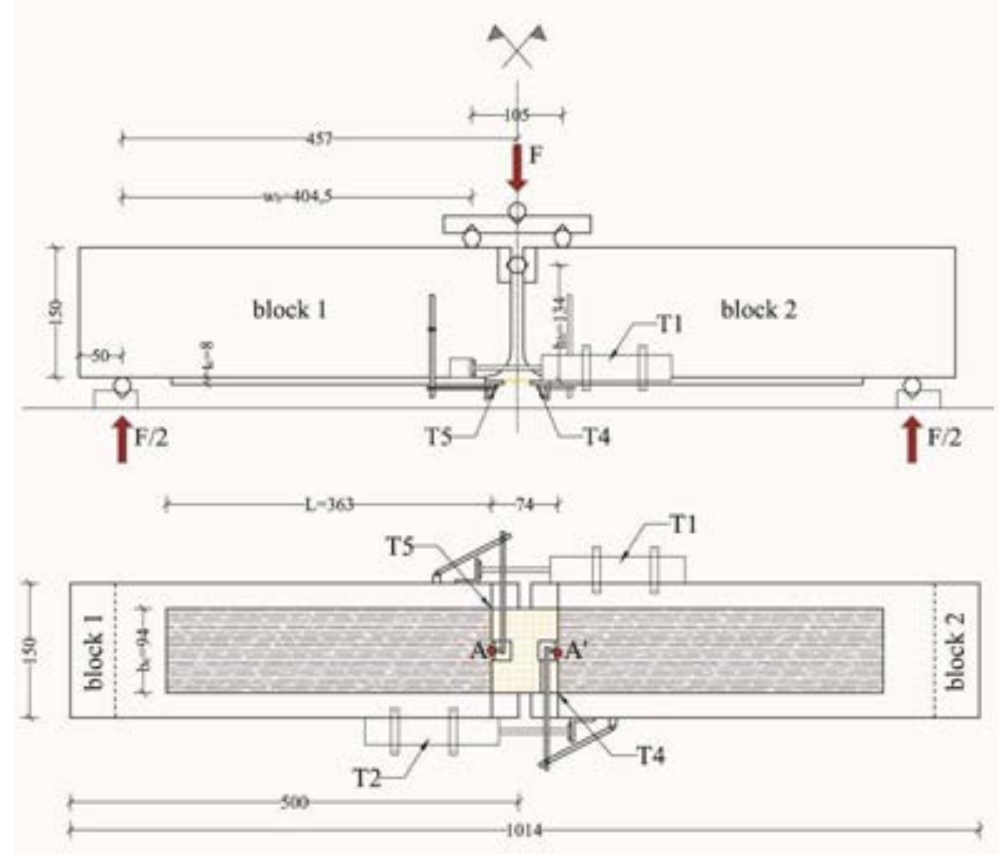

Figure 3. Test setup: (a) front; (b) intrados (dimensions are in millimeters).

The bond length $L$ was greater than the effective bond length $L_{\text {eff }}$ which is approximately 250$280 \mathrm{~mm}$ according to $[25,26,27,30]$. This allowed to reach the debonding load of the reinforcement and therefore to compare the obtained results with those of single-lap shear tests with $L \geq L_{\text {eff }}$ in terms of debonding load. The edges of the concrete blocks were rounded at the intrados of the hinged cross sections to reduce the transverse compressive stresses at the interface associated with the relative rotation between the blocks during the test $[13,32]$. 
The tests were performed with a servohydraulic universal testing machine (Instron) by controlling the displacement of the load application point at a constant rate. During the test the following response parameters were measured: i) the applied force $F$ (Figure 3a); ii) the relative displacement between the blocks at the intrados (transducers T1 and T2 in Figure 3a); iii) the slip of the fibers at mid-span with respect to the two blocks (transducers T4 and T5). In particular transducers T4 and T5 measured the maximum relative displacements between the fibers and the concrete blocks (slips at points $\mathrm{A}$ and $\mathrm{A}^{\prime}$ ), which are referred to as global slips of the interface surfaces. The T1 and T2 transducers were of the CDP (LVDT) type with movable shaft, while the T4 and T5 transducers were of the CE cantilever type. Four displacement rates were used for the force application point: $0.17,0.34,0.51$ and $0.68 \mathrm{~mm} / \mathrm{min}$.

Samples were named $B T \_x \_y f_{\_} z n$, where $x$ indicates the type of textile $(70 / 18,44$, or 105), $y$ the number of yarns, $z$ the displacement rate, and $n$ the number of the sample. The samples are listed in Table 2. At least three nominally equal specimens were tested for each textile and for each rate. Pictures of representative test samples are shown in Figure 4.

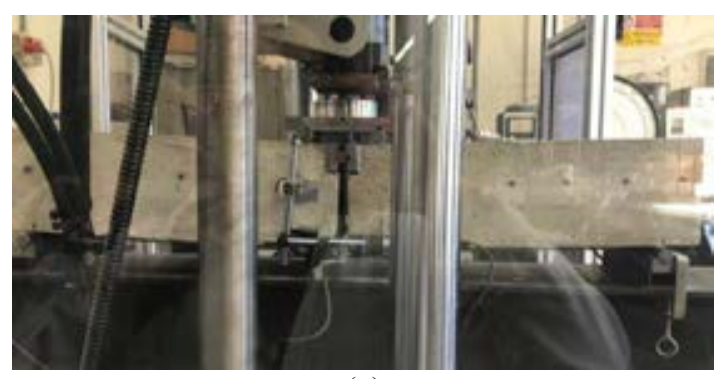

(a)

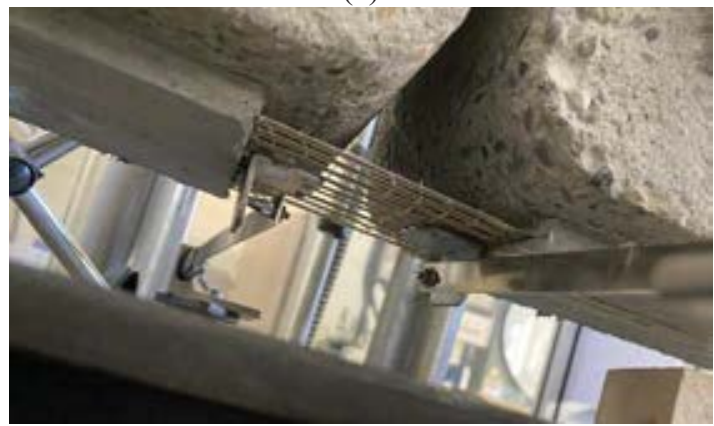

(c)

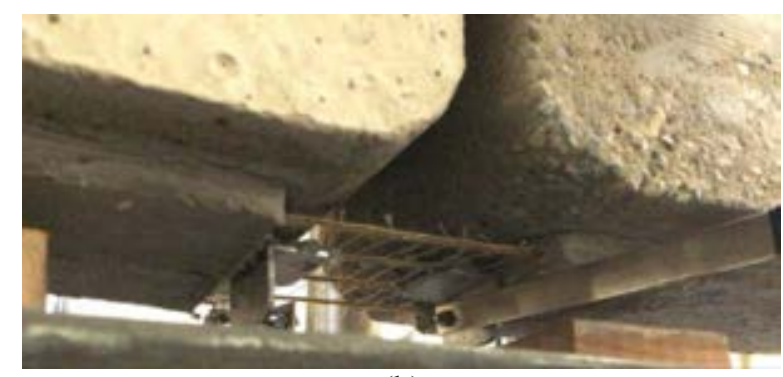

(b)

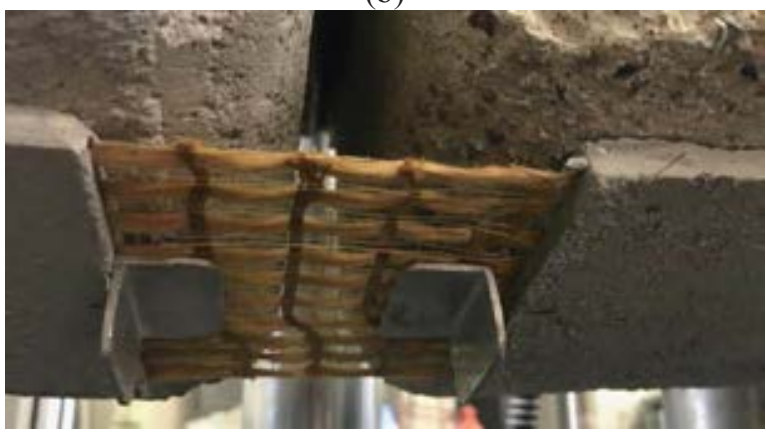

(d)

Figure 4. (a) Test set-up; (b) textile 44; (c) textile 105; (d) textile 70/18.

The adopted displacement rates correspond to nominal slip rates of $0.00085,0.0017$, 0.00255 and $0.0034 \mathrm{~mm} / \mathrm{s}$, respectively. The nominal slip rate associated with each displacement rate were evaluated neglecting the elastic deformation of the concrete blocks (i.e. rigid rotation of blocks was assumed) and assuming symmetric rotation of the two blocks. The lowest displacement rate was chosen to obtain a nominal slip rate similar to the slip rate adopted for the single-lap shear tests presented in [25]. Figure 5a shows the average of the global slips measured by the transducers T4 and T5 of four specimens with textile 74/18 as a function of time. Figure $5 \mathrm{~b}$ shows the slip rate (obtained as the derivative of the corresponding curve of Figure 5a) as a function of time for one specimen. Figure 5 shows that after the initial branch the slip rate tends to be constant and proportional to the displacement rate. Nonetheless the slip rate is significantly different form the nominal value evaluated on the base of the rigid blocks assumption. Furthermore the slip rate is almost constant only at the end of the tests when the deboning has already initiated. 

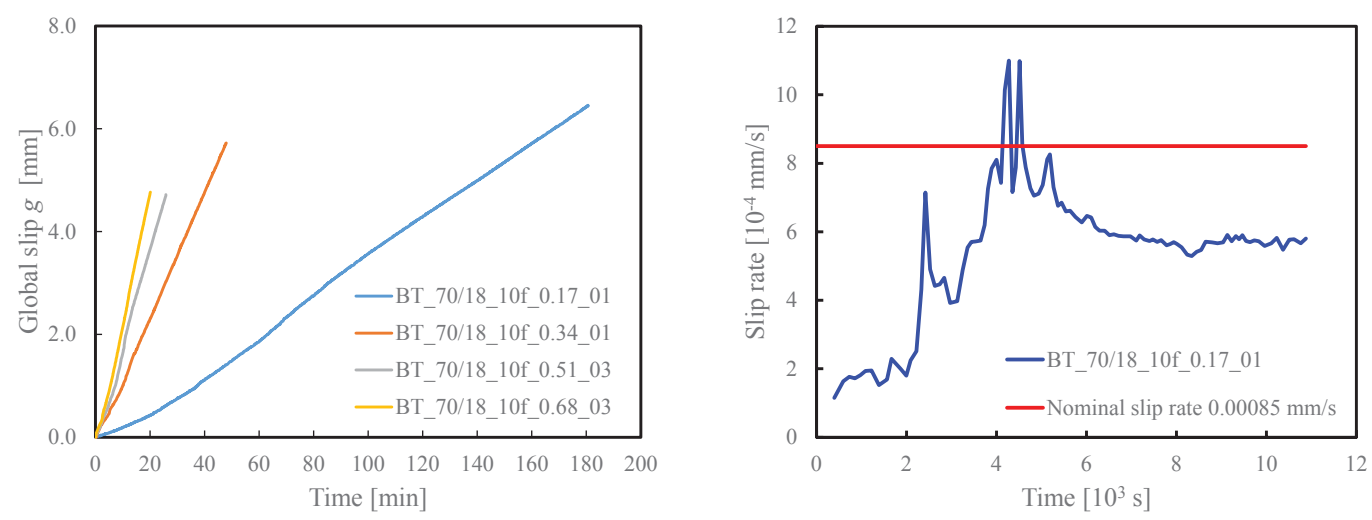

Figure 5. (a) Global slip as a function of time; (b) slip rate as a function of time for specimen BT_70/18_10f_0.17_1.

\section{EXPERIMENTAL RESULTS AND DISCUSSION}

All the specimens failed due to loss of bond at the fiber-matrix interface with high interfacial slip (Figure 4 (b)-(d)). Longitudinal cracks in a plane parallel to the intrados were observed in the matrix in many of the specimens with 10 yarns of textile $70 / 18$, similar cracks were not observed neither in the specimens with 9 yarns of textile 70/18 nor in the specimens with textiles 44 and 105 . With reference to textile $70 / 18$ this is probably related to the ratio between the matrix surface and the textile surface, which is higher in the specimens with 9 yearns compared to the specimens with 10 yarns. With reference to textiles 44 and 105 the lack of longitudinal cracks is probably related to the lack of transverse yarns.

Figure 6 shows a typical experimental response in terms of fiber stress-global slips (transducers T4 and T5) and fiber stress-relative displacement of the blocks at the intrados (average of relative displacements measured by transducers $\mathrm{T} 1$ and $\mathrm{T} 2$ ).

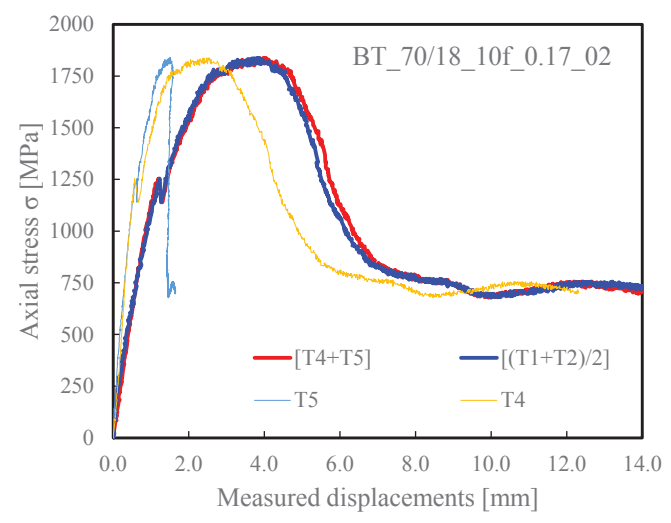

Figure 6. Typical experimental response in terms of fiber stress-measured displacement.

The fiber stress was computed as the ratio between the axial force $N$ in the fibers and the area $A_{f}$ of the fiber cross section. $N$ was computed as a function of the applied force $F$ (Figure 3 ) via equilibrium equations. The global slips measured on the two blocks (points A and A', transducers T4 and T5 in Figure 3b) were similar in the first phase of the loading process, approximately up to a load equal to $50 \%-60 \%$ of the joint capacity. In the second phase of the loading process the global slip increased faster at the loaded end of one of the two interface surfaces (transducer T4 in the case shown in Figure 6) compared to the other interface surface due to the formation and propagation of a crack at the fiber-matrix interface. On this surface 
complete debonding occurred at the end of the test. In this phase the global slip of the other interface surface (transducer T5 in the case shown in Figure 6) stopped or decreased. Figure 6 also shows that the global slips measured by the transducers T4 and T5 are consistent with the relative displacement of the blocks at the intrados, since the sum of these slips equals the average relative displacement measured by the transducers $\mathrm{T} 1$ and $\mathrm{T} 2$.

Table 2 summarizes the specimen characteristics and the experimental results in terms of peak load $F_{\max }$, corresponding tensile force in the fibers referred to as peak force $N_{\max }$, corresponding stress of the fiber referred to as peak stress $\sigma_{\max }$, and global slip of the surface where debonding occurs at the peak load $g_{\max }$.

\begin{tabular}{|c|c|c|c|c|c|c|c|c|c|c|}
\hline Specimen & $\begin{array}{c}n \\
{[--]}\end{array}$ & $\begin{array}{c}b^{*} \\
{[\mathrm{~mm}]}\end{array}$ & $\begin{array}{c}t^{*} \\
{[\mathrm{~mm}]}\end{array}$ & $\begin{array}{c}A_{f} \\
{\left[\mathrm{~mm}^{2}\right]}\end{array}$ & $\begin{array}{l}F_{\max } \\
{[\mathrm{kN}]}\end{array}$ & $\begin{array}{l}N_{\max } \\
{[\mathrm{kN}]}\end{array}$ & $\begin{array}{c}\sigma_{\max } \\
{[\mathrm{MPa}]}\end{array}$ & $\begin{array}{c}\text { Average } \sigma_{\max } \\
{[\mathrm{MPa}]}\end{array}$ & $\begin{array}{c}g_{\max } \\
{[\mathrm{mm}]}\end{array}$ & $\begin{array}{l}\text { Average } g_{\max } \\
{[\mathrm{mm}]}\end{array}$ \\
\hline BT 70/18 10f $0.17 \quad 01$ & 10 & 4 & 0.1066 & 4.26 & 5.35 & 8.08 & 1895 & \multirow{6}{*}{$\begin{array}{c}1727 \\
(\mathrm{CoV}=9 \%)\end{array}$} & 2.257 & \multirow{6}{*}{$\begin{array}{c}2.147 \\
(\mathrm{CoV}=18 \%)\end{array}$} \\
\hline BT $70 / 18$ 10f 0.1702 & 10 & 4 & 0.1066 & 4.26 & 5.19 & 7.84 & 1839 & & 2.532 & \\
\hline BT_70/18_10f_0.17_03 & 10 & 4 & 0.1066 & 4.26 & 5.08 & 7.66 & 1797 & & 2.107 & \\
\hline BT $70 / 18$ 10f $0.17 \quad 04$ & 10 & 4 & 0.1066 & 4.26 & 4.78 & 7.22 & 1694 & & 1.670 & \\
\hline BT 70/18 10f 0.17 05 & 10 & 4 & 0.1066 & 4.26 & 4.12 & 6.21 & 1457 & & 1.729 & \\
\hline BT_70/18_10f_0.17_06 & 10 & 4 & 0.1066 & 4.26 & 4.75 & 7.17 & 1682 & & 2.585 & \\
\hline BT_70/18_10f_0.34_01 & 10 & 4 & 0.1066 & 4.26 & 3.53 & 5.33 & 1250 & \multirow{3}{*}{$\begin{array}{c}1691 \\
(\mathrm{CoV}=23 \%)\end{array}$} & 1.526 & \multirow{3}{*}{$\begin{array}{c}1.886 \\
(\mathrm{CoV}=26 \%)\end{array}$} \\
\hline 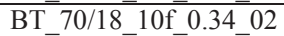 & 10 & 4 & 0.1066 & 4.26 & 5.29 & 7.98 & 1872 & & 1.683 & \\
\hline BT_70/18_10f_0.34_03 & 10 & 4 & 0.1066 & 4.26 & 5.51 & 8.32 & 1952 & & 2.449 & \\
\hline BT_70/18_10f_0.51_01 & 10 & 4 & 0.1066 & 4.26 & 4.74 & 7.16 & 1680 & \multirow{5}{*}{$\begin{array}{c}1529 \\
(\mathrm{CoV}=18 \%)\end{array}$} & 1.941 & \multirow{5}{*}{$\begin{array}{c}1.579 \\
(\mathrm{CoV}=27 \%)\end{array}$} \\
\hline BT_70/18_10f_0.51_02 & 10 & 4 & 0.1066 & 4.26 & 3.90 & 5.89 & 1382 & & 1.615 & \\
\hline BT_70/18_10f_0.51_03 & 10 & 4 & 0.1066 & 4.26 & 5.19 & 7.84 & 1839 & & 1.763 & \\
\hline BT_70/18_10f_0.51_04 & 10 & 4 & 0.1066 & 4.26 & 3.24 & 4.88 & 1145 & & 1.700 & \\
\hline BT_70/18_10f_0.51_05 & 10 & 4 & 0.1066 & 4.26 & 4.51 & 6.81 & 1598 & & 0.859 & \\
\hline BT_70/18_10f_0.68_01 & 10 & 4 & 0.1066 & 4.26 & 6.32 & 9.54 & 2238 & \multirow{5}{*}{$\begin{array}{c}2243 \\
(\mathrm{CoV}=16 \%)\end{array}$} & 1.994 & \multirow{5}{*}{$\begin{array}{c}2.527 \\
(\mathrm{CoV}=16 \%)\end{array}$} \\
\hline BT $70 / 18 \quad 10 f \quad 0.68 \quad 02$ & 10 & 4 & 0.1066 & 4.26 & 7.49 & 11.3 & 2651 & & 2.569 & \\
\hline BT_70/18_10f_0.68_03 & 10 & 4 & 0.1066 & 4.26 & 7.23 & 10.91 & 2559 & & 2.568 & \\
\hline BT_70/18_10f_0.68_04 & 10 & 4 & 0.1066 & 4.26 & 5.44 & 8.21 & 1926 & & 2.407 & \\
\hline BT $70 / 18$ 10f $0.68 \quad 05$ & 10 & 4 & 0.1066 & 4.26 & 5.20 & 7.85 & 1842 & & 3.099 & \\
\hline BT_70/18_9f_0.68_01 & 9 & 4 & 0.1066 & 3.84 & 6.11 & 9.22 & 2403 & \multirow{3}{*}{$\begin{array}{c}2260 \\
(\mathrm{CoV}=6 \%)\end{array}$} & 2.232 & \multirow{3}{*}{$\begin{array}{c}2.661 \\
(\mathrm{CoV}=14 \%)\end{array}$} \\
\hline BT_70/18_9f_0.68_02 & 9 & 4 & 0.1066 & 3.84 & 5.48 & 8.27 & 2156 & & 2.880 & \\
\hline BT_70/18_9f_0.68_03 & 9 & 4 & 0.1066 & 3.84 & 5.65 & 8.52 & 2221 & & 2.870 & \\
\hline BT_44_4f_0.68_01 & 4 & 4 & 0.16575 & 2.65 & 3.83 & 5.78 & 2179 & \multirow{3}{*}{$\begin{array}{c}2046 \\
(\mathrm{CoV}=7 \%)\end{array}$} & 2.821 & \multirow{3}{*}{$\begin{array}{c}3.088 \\
(\mathrm{CoV}=12 \%)\end{array}$} \\
\hline BT_44_4f_0.68_02 & 4 & 4 & 0.16575 & 2.65 & 3.60 & 5.44 & 2051 & & 2.937 & \\
\hline BT_44_4f_0.68_03 & 4 & 4 & 0.16575 & 2.65 & 3.36 & 5.06 & 1908 & & 3.505 & \\
\hline BT_105_9f_0.68_01 & 9 & 4 & 0.15145 & 5.45 & 9.28 & 14.01 & 2570 & \multirow{3}{*}{$\begin{array}{c}2516 \\
(\mathrm{CoV}=2 \%)\end{array}$} & 3.589 & \multirow{3}{*}{$\begin{array}{c}3.610 \\
(\mathrm{CoV}=6 \%)\end{array}$} \\
\hline BT_105_9f_0.68_02 & 9 & 4 & 0.15145 & 5.45 & 9.03 & 13.63 & 2500 & & 3.845 & \\
\hline BT_1059ff $0.68 \quad 03$ & 9 & 4 & 0.15145 & 5.45 & 8.95 & 13.51 & 2478 & & 3.397 & \\
\hline
\end{tabular}

Table 2. Peak load $F_{\max }$ and corresponding axial force $N_{\max }$, axial stress $\sigma_{\max }$, and global slip $g_{\max }$ of the tested specimens.

The average peak stress of textile $70 / 18$ is between $1529 \mathrm{MPa}$ (displacement rate 0.51 $\mathrm{mm} / \mathrm{min}$ ) and $2260 \mathrm{MPa}$ (displacement rate $0.68 \mathrm{~mm} / \mathrm{min}$ ). The corresponding coefficients of variation $(\mathrm{CoV})$ are equal to $18 \%$ and $6 \%$, respectively. The slip at the peak load is between $1.57 \mathrm{~mm}$ (displacement rate $0.51 \mathrm{~mm} / \mathrm{min}, \mathrm{CoV}=27 \%$ ) and $2.66 \mathrm{~mm}$ (rate $0.68 \mathrm{~mm} / \mathrm{min}$, $\mathrm{CoV}=14 \%)$. The average peak stress of textiles 44 and 105 are $2046 \mathrm{MPa}(\mathrm{CoV}=7 \%)$ and $2516 \mathrm{MPa}(\mathrm{CoV}=2 \%)$. The global slip at the peak load exceeds $3 \mathrm{~mm}$ for these textiles.

The $\sigma-g$ responses of the tested specimens are shown in Figure 7 where the fibers tensile stress $\sigma$ is reported as a function of the global slip $g$ of the interface surface on which the debonding occurs (maximum of the global slips measured by the transducers T4 and T5). The experimental $\sigma-g$ responses shown in Figure 7 are consistent with the idealized $\sigma-g$ response shown in Figure 8a, which is associated with the typical CML shown in Fig 8b [26] and with a bonded length equal to or longer than the effective bond length. 

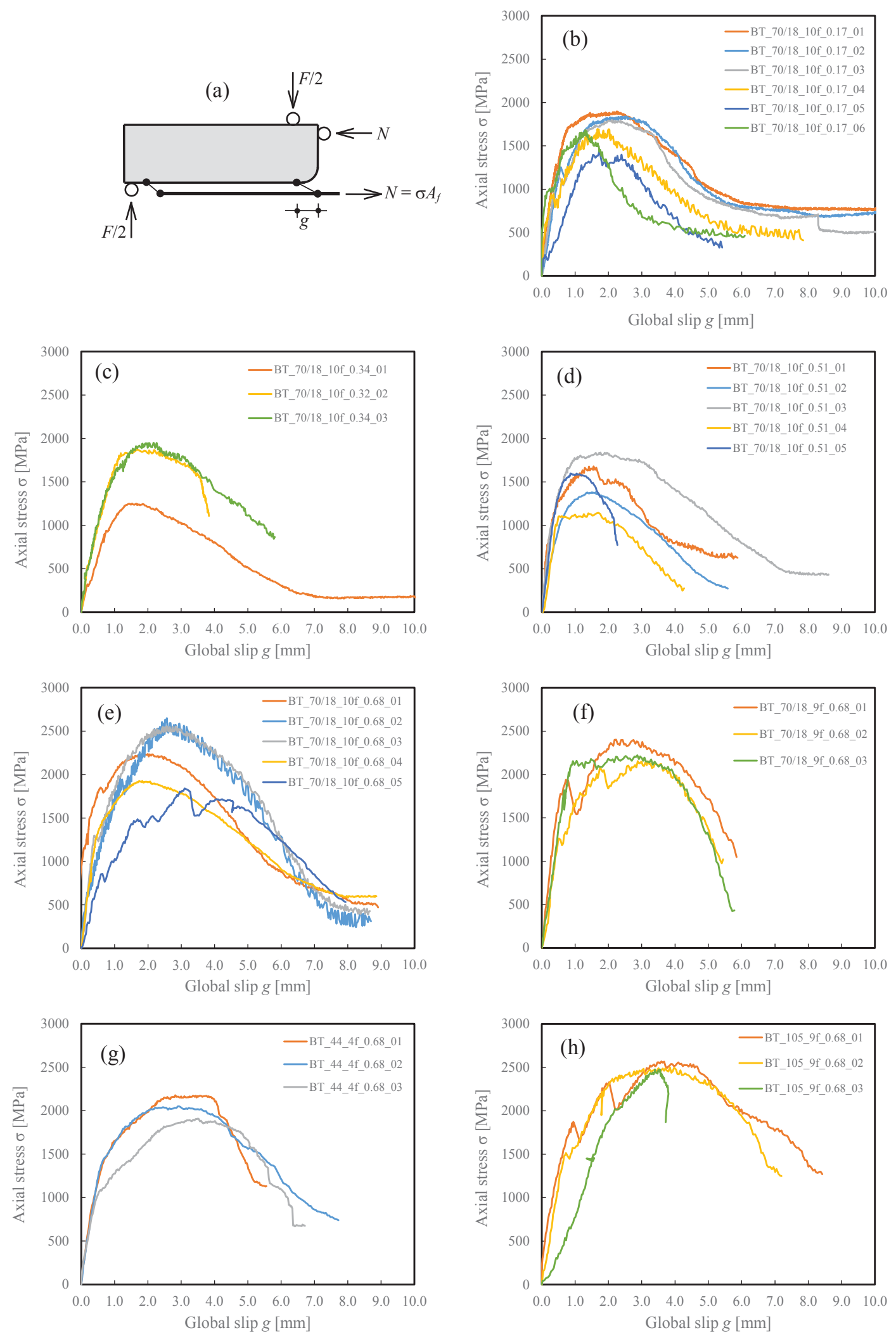

Figure 7. (a) Beam test; (b)-(h) $\sigma-g$ responses of the tested specimens. 

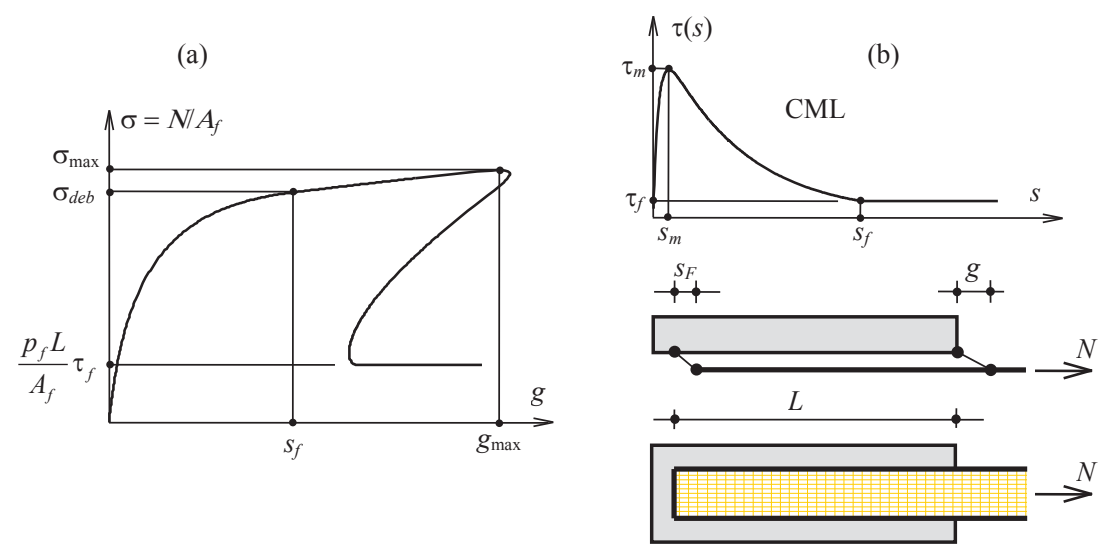

Figure 8. (a) Idealized $\sigma-g$ response; (b) typical CML.

This response curve exhibits an ascending branch up to the debonding stress $\sigma_{d e b}$, which correspond to the onset of the interfacial crack propagation that occurs for a global slip equal to $s_{f}$ (Figure $8 \mathrm{~b}$ ). A further ascending branch, up to the peak stress $\sigma_{\max }$, is exhibited if a constant friction branch follows the slip $s_{f}$ in the CML and the bonded length is longer than the effective bond length. The slope of this branch is related to the friction shear stress $\tau_{f}$ (Figure $8 b$ ). Once the peak stress is attained the applied stress decreases until it reaches a constant value due to friction only. The snap back phenomenon shown in Figure 8a, which is due to the elastic energy release associated with the decrease of the force $N$, is not experimentally caught by the performed beam tests since they are controlled by the displacement of the load application point.

An initial linear branch is exhibited by all the $\sigma-g$ responses shown in Figure 7 whose slope is related neither to the type of textile nor to the displacement rate. This branch is followed by an ascending branch with a smaller slope up to the onset of the debonding phenomenon. Once the debonding initiates the increase of the load up to the peak stress $\sigma_{\max }$ is associated with the development of friction shear stress [26] in the debonded region near to the loaded end. The descending branch is associated with the increase of the length of the debonded zone up to the complete debonding and the attainement of a constant stress associated with the interfacial friction shear stress $\tau_{f}$ [25]. It should be noted that some beam tests were stopped before reaching the friction branch to save time.

Figure 9 compares the $\sigma-g$ responses of beam test on textile $70 / 18$, characterized by a nominal slip rate equal to $0.00085 \mathrm{~mm} / \mathrm{s}$, with the $\sigma-g$ responses obtained by D'Antino et al. [25] on the same composite through single-lap shear tests at the slip rate of $0.00084 \mathrm{~mm} / \mathrm{s}$ with a bonded length equal to $330 \mathrm{~mm}$. Similar responses are obtained with the single-lap and beam tests. In particular the performed beam tests provided a slightly lower peak stress and corresponding global slip and a slightly higher friction stress compared to the values of the corresponding parameters provided by single-lap shear tests. The mentioned differences between the results of these tests are not fully consistent with the experimental results presented by Calabrese et al. [33]. In [33] it is observed that beam tests and single-lap shear tests provide similar peak stress, while beam tests provide friction stress that are roughly the double of those provided by single-lap shear test. 


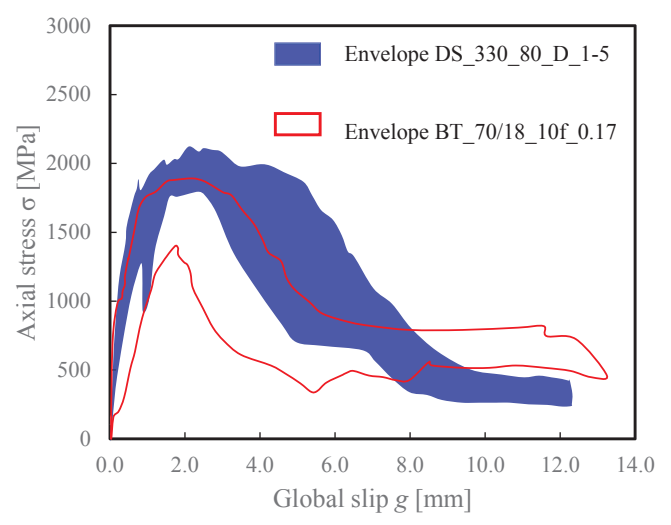

Figure 9. Comparison between the $\sigma-g$ responses obtained with beam tests and the $\sigma$ - $g$ responses obtained by D'Antino et al. [25] through single-lap shear tests.

The higher friction stress obtained with beam tests is attributed by the authors of [33] to the transversal compressive stress on the textile at the edge of the blocks (at the mid-span of the specimen) associated with their rotation. The edges of the concrete blocks were rounded at the intrados of the hinged cross sections to reduce the transversal stress on the textile when the blocks rotate. This could explain the difference between the results presented in [33] and the results presented in this paper.

The influence of the displacement rate is shown in Figure 10 in which the peak stress (Figure 10a) and the corresponding global slip (Figure 10b) are reported as a function of the nominal slip rate.

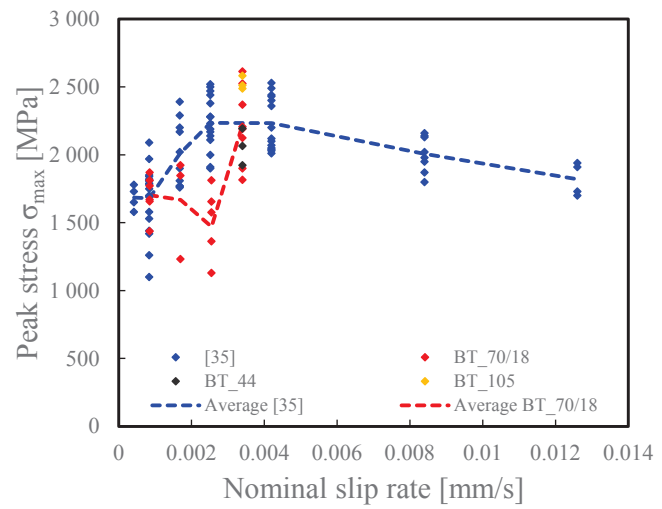

(a)

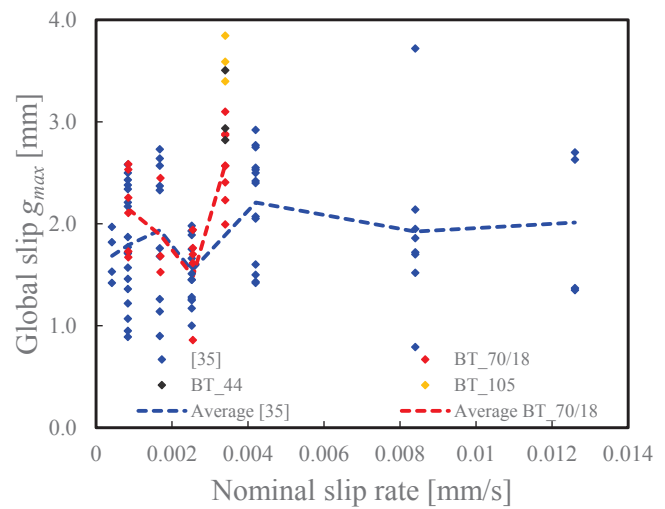

(b)

Figure 10. Influence of the slip rate: (a) peak stress vs. slip rate; (b) global slip at peak load vs. slip rate.

In Figure 10 the experimental results are also compared with those obtained by Carloni et. al. [35] with single-lap shear tests. Experimental peak stress of single-lap shear tests presented in [35] refer to bonded length equal to $330 \mathrm{~mm}$ and $430 \mathrm{~mm}$. It can be observed that the dependencies of the peak stress and corresponding global slip on the slip rate are different from those presented in [35], even if the peak stress corresponding to the slip rate $0.0025 \mathrm{~mm} / \mathrm{s}$ is similar. The difference between the results of beam tests and the results reported in [35] is probably due to the different test procedure adopted. Indeed the single-lap shear tests presented in [35] are performed imposing a constant rate of the global slip, while the beam tests are performed imposing a constant rate of the load application point. As discussed in section 2.2 the slip rate approaches to a constant value only at an advanced stage of the test (Figure 3 ). This makes the beam test configuration unsuitable for investigating the influence of the load- 
ing rate on the interfacial stress transfer phenomenon, unless the tests are controlled by the global slip measured through the transducers T4 and T5.

Figure 11 shows the comparison among the $\sigma-g$ responses of the three utilized textiles. It can be observed that the response curves of textiles 44 and 105 are similar to those of textile 70/18. Textile 105 is characterized by slightly higher slip at peak load than those of 70/18.

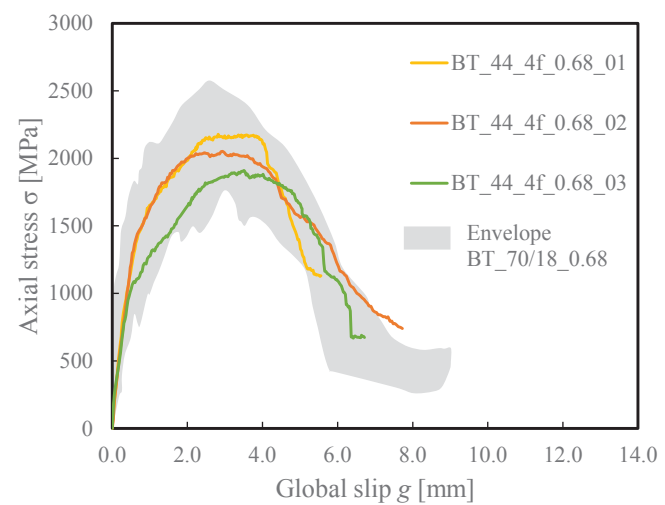

(a)

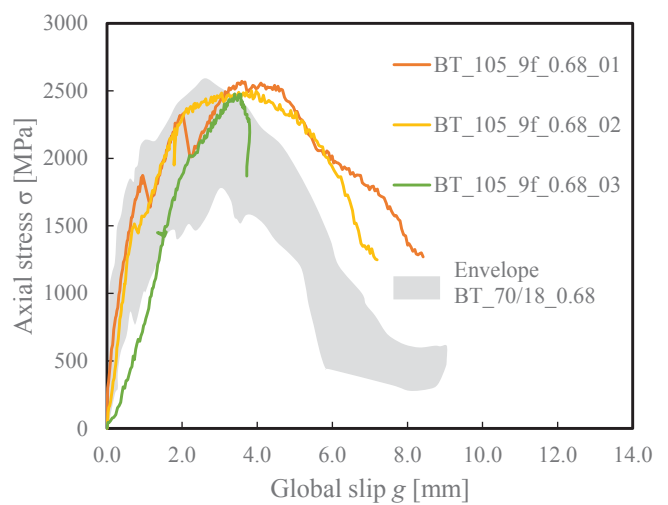

(b)

Figure 11. Effect of the fiber arrangement on the $\sigma-g$ responses: (a) textile 44 vs. textile 70/18; (b) textile 105 vs. textile $70 / 18$.

\section{CONCLUSIONS}

This paper presents the results of the first step of an experimental campaign for the characterization of the bond between PBO-FRCM materials and concrete by means of beam tests. Three composite materials made of the same matrix and different PBO textiles were tested. The tests were performed with different loading rates. The following conclusions can be drawn.

1. Beam tests provided experimental responses similar to those obtained by several authors through single-lap shear tests.

2. The fiber stress associated with the friction at the fiber-matrix interface was lower than that obtained by other authors with similar tests. This difference can be ascribed to the geometrical characteristics of the employed specimen.

3. It was not possible to observe a clear dependence of the joint capacity and the corresponding global slip on the loading rate. Therefore beam test does not appear suitable for evaluating the effect of the loading rate on the bond properties of PBO-FRCM materials, unless they are performed controlling the relative displacement between the concrete blocks or the interfacial slip at the mid-span of the specimen.

4. Textiles of PBO fibers with different fiber amounts have comparable responses in terms of shear stress transfer mechanism in the investigated range.

The beam test appears to be an alternative to single-lap or double-lap shear tests to characterize the interface between FRCM materials and the substrate. However further investigations are needed to determine the influence of the geometry of the specimen and the test procedure on the measured parameters. 


\section{ACKNOWLEDGMENTS}

The authors greatly acknowledge Ruregold s.r.l. (Italy) for providing the composite materials used in this experimental work.

\section{REFERENCES}

[1] Italian National Research Council (CNR), 'Guide for the Design and Construction of Externally Bonded FRP Systems for Strengthening Existing Structures'. CNR - Rome, Italy, 2004.

[2] ACI Committee 440.1R-15, 'Guide for the Design and Construction of Structural Concrete Reinforced with Fiber-Reinforced Polymer (FRP) Bars'. ACI 440.1R-15, Farmington Hill, US, 2015.

[3] Italian National Research Council (CNR), 'Guide for the Design and Construction of Externally Bonded Fibre Reinforced Inorganic Matrix Systems for Strengthening Existing Structures'. CNR - Rome, Italy, 2020.

[4] ACI Committee 549, 'Guide to Design and construction of externally bonded fabricreinforced cementitious matrix (FRCM) systems for repair and strengthening concrete and masonry structures'. ACI 549.4R-13, Farmington Hill, US, 2013.

[5] G. Loreto, L. Leardini, D. Arboleda, and A. Nanni, 'Performance of RC Slab-Type Elements Strengthened with Fabric-Reinforced Cementitious-Matrix Composites', J. Compos. Constr., vol. 18, no. 3, Jun. 2014, doi: 10.1061/(ASCE)CC.1943-5614.0000415.

[6] S. Babaeidarabad, G. Loreto, and A. Nanni, 'Flexural Strengthening of RC Beams with an Externally Bonded Fabric-Reinforced Cementitious Matrix', J. Compos. Constr., vol. 18, no. 5, p. 04014009, Oct. 2014, doi: 10.1061/(ASCE)CC.1943-5614.0000473.

[7] C. Escrig, L. Gil, and E. Bernat-Maso, 'Experimental comparison of reinforced concrete beams strengthened against bending with different types of cementitious-matrix composite materials', Construction and Building Materials, vol. 137, pp. 317-329, Apr. 2017, doi: 10.1016/j.conbuildmat.2017.01.106.

[8] F. Bencardino, C. Carloni, A. Cordello, F. Focacci, A. Napoli, and R. Realfonso, 'Flexural behaviour of RC members strengthened with FRCM: State-of-the-art and predictive formulas', Composites Part B: Engineering, vol. 148, pp. 132-148, Sep. 01, 2018.

[9] L. Ombres, 'Structural performances of reinforced concrete beams strengthened in shear with a cement based fiber composite material', Composite Structures, vol. 122, pp. 316329, Apr. 2015, doi: 10.1016/j.compstruct.2014.11.059.

[10] A. D'Ambrisi and F. Focacci, 'Flexural Strengthening of RC Beams with CementBased Composites', J. Compos. Constr., vol. 15, no. 5, pp. 707-720, Oct. 2011, doi: 10.1061/(ASCE)CC.1943-5614.0000218.

[11] Z. C. Tetta, L. N. Koutas, and D. A. Bournas, 'Textile-reinforced mortar (TRM) versus fiber-reinforced polymers (FRP) in shear strengthening of concrete beams', Composites Part B: Engineering, vol. 77, pp. 338-348, Aug. 2015, doi: 10.1016/j.compositesb.2015.03.055. 
[12] Tetta, Zoi C., Triantafillou, Thanasis C., and Bournas, Dionysios A., 'On the design of shear-strengthened RC members through the use of textile reinforced mortar overlays', Composites Part B: Engineering, vol. 147, pp. 178-196, Aug. 15, 2018.

[13] T. D'Antino, F. Focacci, L. H. Sneed, and C. Carloni, 'Relationship between the effective strain of PBO FRCM-strengthened RC beams and the debonding strain of direct shear tests', Engineering Structures, vol. 216, p. 110631, Aug. 2020, doi: 10.1016/j.engstruct.2020.110631.

[14] Consiglio Superiore dei Lavori Pubblici - Servizio Tecnico Centrale, 'Linea Guida per la identificazione, la qualificazione ed il controllo di accettazione di compositi fibrorinforzati a matrice inorganica (FRCM) da utilizzarsi per il consolidamento strutturale di costruzioni esistenti'. Consiglio Superiore dei Lavori Pubblici - Servizio Tecnico Centrale, Dec. 2018.

[15] AC 434-13, 'Acceptance criteria for masonry and concrete strengthening using fabricreinforced cementitious matrix (FRCM) composite systems'. 2013.

[16] C. Carloni and K. V. Subramaniam, 'FRP-Masonry Debonding: Numerical and Experimental Study of the Role of Mortar Joints', J. Compos. Constr., vol. 16, no. 5, pp. 581-589, Oct. 2012, doi: 10.1061/(ASCE)CC.1943-5614.0000282.

[17] M. Malena, F. Focacci, C. Carloni, and G. de Felice, 'The effect of the shape of the cohesive material law on the stress transfer at the FRP-masonry interface', Composites Part B: Engineering, vol. 110, pp. 368-380, Feb. 2017, doi: 10.1016/j.compositesb.2016.11.012.

[18] M. Bocciarelli and M. A. Pisani, 'Survey on the interface behaviour in reinforced concrete beams strengthened with externally bonded FRP reinforcement', Composites Part B: Engineering, vol. 118, pp. 169-176, Jun. 2017, doi: 10.1016/j.compositesb.2017.02.047.

[19] C. Carloni et al., 'Fiber Reinforced Composites with Cementitious (Inorganic) Matrix', in Design Procedures for the Use of Composites in Strengthening of Reinforced Concrete Structures, vol. 19, C. Pellegrino and J. Sena-Cruz, Eds. Dordrecht: Springer Netherlands, 2016, pp. 349-392.

[20] L. Ombres, 'Analysis of the bond between Fabric Reinforced Cementitious Mortar (FRCM) strengthening systems and concrete', Composites Part B: Engineering, vol. 69, pp. 418-426, Feb. 2015, doi: 10.1016/j.compositesb.2014.10.027.

[21] L. Ascione, G. de Felice, and S. De Santis, 'A qualification method for externally bonded Fibre Reinforced Cementitious Matrix (FRCM) strengthening systems', Composites Part B: Engineering, vol. 78, pp. 497-506, Sep. 2015, doi: 10.1016/j.compositesb.2015.03.079.

[22] L. H. Sneed, T. D'Antino, C. Carloni, and C. Pellegrino, 'A comparison of the bond behavior of PBO-FRCM composites determined by double-lap and single-lap shear tests', Cement and Concrete Composites, vol. 64, pp. 37-48, Nov. 2015, doi: 10.1016/j.cemconcomp.2015.07.007.

[23] F. G. Carozzi et al., 'Experimental investigation of tensile and bond properties of Carbon-FRCM composites for strengthening masonry elements', Composites Part B: Engineering, vol. 128, pp. 100-119, Nov. 2017, doi: 10.1016/j.compositesb.2017.06.018.

[24] C. Caggegi et al., 'Experimental analysis on tensile and bond properties of PBO and aramid fabric reinforced cementitious matrix for strengthening masonry structures', Composites Part B: Engineering, vol. 127, pp. 175-195, Oct. 2017, doi: 10.1016/j.compositesb.2017.05.048. 
[25] T. D'Antino, C. Carloni, L. H. Sneed, and C. Pellegrino, 'Matrix-fiber bond behavior in PBO FRCM composites: A fracture mechanics approach', Engineering Fracture Mechanics, vol. 117, pp. 94-111, Feb. 2014, doi: 10.1016/j.engfracmech.2014.01.011.

[26] F. Focacci, T. D'Antino, C. Carloni, L. H. Sneed, and C. Pellegrino, 'An indirect method to calibrate the interfacial cohesive material law for FRCM-concrete joints', Materials \& Design, vol. 128, pp. 206-217, Aug. 2017, doi: 10.1016/j.matdes.2017.04.038.

[27] A. D'Ambrisi, L. Feo, and F. Focacci, 'Experimental analysis on bond between PBOFRCM strengthening materials and concrete', Composites Part B: Engineering, vol. 44, no. 1, pp. 524-532, Jan. 2013, doi: 10.1016/j.compositesb.2012.03.011.

[28] M. R. Valluzzi et al., 'Round Robin Test for composite-to-brick shear bond characterization', Mater Struct, vol. 45, no. 12, pp. 1761-1791, Dec. 2012, doi: 10.1617/s11527-0129883-5.

[29] S. De Santis et al., 'Round Robin Test on tensile and bond behaviour of Steel Reinforced Grout systems', Composites Part B: Engineering, vol. 127, pp. 100-120, Oct. 2017, doi: 10.1016/j.compositesb.2017.03.052.

[30] A. D'Ambrisi, L. Feo, and F. Focacci, 'Bond-slip relations for PBO-FRCM materials externally bonded to concrete', Composites Part B: Engineering, vol. 43, no. 8, pp. 29382949, Dec. 2012, doi: 10.1016/j.compositesb.2012.06.002.

[31] F. Focacci, T. D'Antino, and C. Carloni, 'The role of the fiber-matrix interfacial properties on the tensile behavior of FRCM coupons', Construction and Building Materials, vol. 265, p. 120263, Dec. 2020, doi: 10.1016/j.conbuildmat.2020.120263.

[32] A. S. Calabrese, P. Colombi, and T. D'Antino, 'A Bending Test Set-Up for the Investigation of the Bond Properties of FRCM Strengthenings Applied to Masonry Substrates', $K E M$, vol. 817, pp. 149-157, Aug. 2019, doi: 10.4028/www.scientific.net/KEM.817.149.

[33] A. S. Calabrese, T. D'Antino, P. Colombi, and C. Poggi, 'Study of the influence of interface normal stresses on the bond behavior of FRCM composites using direct shear and modified beam tests', Construction and Building Materials, vol. 262, p. 120029, Nov. 2020, doi: 10.1016/j.conbuildmat.2020.120029.

[34] A. S. Calabrese, T. D'Antino, and P. Colombi, 'Experimental and analytical investigation of PBO FRCM-concrete bond behavior using direct and indirect shear test set-ups', Composite Structures, vol. 267, p. 113672, Jul. 2021, doi: 10.1016/j.compstruct.2021.113672.

[35] C. Carloni, S. Verre, L. H. Sneed, and L. Ombres, 'Loading rate effect on the debonding phenomenon in fiber reinforced cementitious matrix-concrete joints', Composites Part B: Engineering, vol. 108, pp. 301-314, Jan. 2017, doi: 10.1016/j.compositesb.2016.09.087.

[36] UNI EN 1015-11:2019, 'Metodi di prova per malte per opere murarie - Parte 11: Determinazione della resistenza a flessione e a compressione della malta indurita'. UNI EN, 2019.

[37] UNI EN 12390-3:2019, 'Prove sul calcestruzzo indurito - Parte 3: Resistenza alla compressione dei provini'. UNI EN, 2019. 